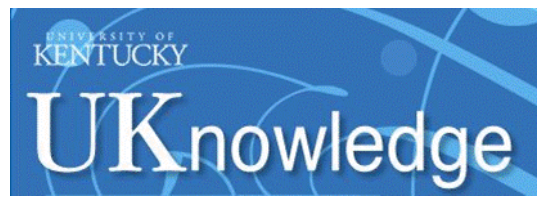

University of Kentucky

UKnowledge

\title{
Large-Scale Optimization of Synchronous Reluctance Machines Using CE-FEA and Differential Evolution
}

\author{
Yi Wang \\ University of Kentucky \\ Dan M. Ionel \\ University of Kentucky, dan.ionel@uky.edu \\ Vandana Rallabandi \\ University of Kentucky, vandana.rallabandi@uky.edu \\ Minjie Jiang \\ Regal Beloit Corporation \\ Steven Stretz \\ Regal Beloit Corporation
}

Follow this and additional works at: https://uknowledge.uky.edu/peik_facpub

Part of the Power and Energy Commons

Right click to open a feedback form in a new tab to let us know how this document benefits you.

\section{Repository Citation}

Wang, Yi; Ionel, Dan M.; Rallabandi, Vandana; Jiang, Minjie; and Stretz, Steven, "Large-Scale Optimization of Synchronous Reluctance Machines Using CE-FEA and Differential Evolution" (2016). Power and Energy Institute of Kentucky Faculty Publications. 47.

https://uknowledge.uky.edu/peik_facpub/47

This Article is brought to you for free and open access by the Power and Energy Institute of Kentucky at UKnowledge. It has been accepted for inclusion in Power and Energy Institute of Kentucky Faculty Publications by an authorized administrator of UKnowledge. For more information, please contact UKnowledge@lsv.uky.edu. 


\title{
Large-Scale Optimization of Synchronous Reluctance Machines Using CE-FEA and Differential Evolution
}

\author{
Digital Object Identifier (DOI) \\ https://doi.org/10.1109/TIA.2016.2591498
}

\section{Notes/Citation Information}

Published in IEEE Transactions on Industry Applications, v. 52 , issue 6.

(C) 2016 IEEE Copyright Notice. "Personal use of this material is permitted. Permission from IEEE must be obtained for all other uses, in any current or future media, including reprinting/republishing this material for advertising or promotional purposes, creating new collective works, for resale or redistribution to servers or lists, or reuse of any copyrighted component of this work in other works."

The document available for download is the authors' manuscript version that is accepted for publication. The final published version is copyrighted by IEEE and available as: Y. Wang, D. M. Ionel, V. Rallabandi, M. Jiang and S. J. Stretz, "Large-Scale Optimization of Synchronous Reluctance Machines Using CE-FEA and Differential Evolution," in IEEE Transactions on Industry Applications, vol. 52, no. 6, pp. 4699-4709, Nov.Dec. 2016, doi: 10.1109/TIA.2016.2591498 


\title{
Large Scale Optimization of Synchronous Reluctance Machines Using CE-FEA and Differential Evolution
}

\author{
Yi Wang, Dan M. Ionel, Fellow, IEEE, Vandana Rallabandi, Minjie Jiang, Member, IEEE, and \\ Steve Stretz, Member, IEEE
}

\begin{abstract}
A novel automated design optimization procedure based on the application of an ultra-fast computationally-efficient finite element method (CE-FEA) for current regulated synchronous reluctance machines supplied from power electronic converters is proposed. The CE-FEA uses only a minimum number of magnetostatic solutions in order to comprehensively evaluate performance, including ripple torque and core losses. The optimization algorithm is based on differential evolution and uses as independent variables the torque angle and ratios for a generic rotor topology with four flux barriers. Two problems, one with two and another one with three objectives, are studied and results compared. Global performance indices and objectives incorporate the effect of average torque output, losses, torque ripple, and power factor at fixed cost. It is shown that through optimal studies with more than 5,000 candidate designs, high output power, high efficiency, and low torque ripple can be achieved, while the relatively low power factor remains an inherent limitation of synchronous reluctance technology. Simulations are validated versus tests from a $10 \mathrm{hp} 1,800 \mathrm{rpm}$ prototype.

Index Terms - - electric machine, synchronous reluctance motor, differential evolution, electromagnetic finite element analysis, design optimization, CE-FEA.
\end{abstract}

\section{INTRODUCTION}

In the 90's, studies of synchronous reluctance (SynRel) machines included analytical models and performance optimization for radially laminated versions with multiple flux barriers, e.g. [1], and novel constructions of the axiallylaminated type, e.g. [2]. Over the years, the performance was improved through R\&D efforts, such that recently, highefficiency SynRel motors for a wide range of powers have been reported, e.g. [3].

Design optimization of SynRel represents a timely topic that has received continued attention. One of the first studies of the kind, which employed finite element analysis (FEA), was published by Kamper et al. considering two objective functions, namely torque and torque per $\mathrm{kVA}$, and used stator and rotor geometric parameters as inputs [4]. Baek et al. optimized the stator and rotor geometries of a PM assisted

Yi Wang was with University of Wisconsin - Milwaukee, WI, and is now with AvePoint, Changchun, Jilin, 130000, China (e-mail: wangyisnow@gmail.com)

Dan M. Ionel is with Regal Beloit Corporation, Grafton, WI, 53024, USA and with Marquette University and with University of Wisconsin in Milwaukee, WI, 53211, USA (e-mail: dan.ionel@ regalbeloit.com)

Minjie Jiang is with Regal Beloit Corporation, Wausau, WI, 54401, USA (email: Minjie.Jiang@regalbeloit.com)

Steve Stretz is with Regal Beloit Corporation, Grafton, WI, 53024, USA (email: Steve.Stretz@regalbeloit.com).

Authors' manuscript version. The final published version is copyrighted by IEEE and available as: Y. Wang, D. M. Ionel, V. Rallabandi, M. Jiang and S. J. Stretz, "Large-Scale Optimization of Synchronous Reluctance Machines Using CE-FEA and Differential Evolution," in IEEE Transactions on Industry Applications, vol. 52, no. 6, pp. 4699-4709, Nov.-Dec. 2016, doi: 10.1109/TIA.2016.2591498 (C)2016 IEEE Copyright Notice. "Personal use of this material is permitted. Permission from IEEE must be obtained for all other uses, in any current or future media, including reprinting/republishing this material for advertising or promotional purposes, creating new collective works, for resale or redistribution to servers or lists, or reuse of any copyrighted component of this work in other works."
SynRel motor using Differential Evolution (DE) and a lumped parameter model instead of FEA [5]. More recently, Cupertino et al. used magnetostatic FEA solutions over one slot pitch to evaluate motor performance together with a multi-objective optimization of the rotor geometry [6]. Gamba et al. drew on DE to solve a multi-objective optimization problem, where the average torque and torque ripple served as objective functions and the rotor barrier shape is used for input [7], while Howard et. al employed asymmetric flux barriers to maximize the average torque and minimize the torque ripple [8,9]. Bianchi et al. reported on the use of genetic algorithms to minimize the torque ripple in SynRel and PM assisted SynRel motors. A detailed study regarding the geometric parameters affecting torque ripple was also reported therein [10]. Geunther and Hoffmann presented a special optimization of SyRel motors for use in electric vehicles [11], while Loubser and Kamper discussed the combined optimization of a SynRel along with its drive [12]. Howard and Kamper provided a multi-objective, two-stage optimization with torque and torque ripple as objective functions [13].

In order to avoid the use of computationally-expensive timestepped FEA, several static solutions were used for the evaluation of torque and torque ripple in many of these publications. In some papers, 2D FEA was minimally used in combination with surrogate models. An instance of such a work was published by Sato et al, wherein the optimization of a SynRel using normalized gaussian neural networks was discussed [14]. In the work reported therein, the rotor geometry was optimized for maximum torque and minimum iron loss. Iron loss was computed by 1D FEA. Mohammadi et al. discussed the use of a surrogate model based on Bayesian regularization backproportion neural network for optimization of the rotor design of a SynRel motor, which led to considerable savings of computational time [15]. This model used original data acquired from a time stepped FEA.

The present paper, which expands upon a related and previously published conference paper by the same authors [16], brings new contributions in several areas. Firstly, a highly effective modified multi-objective optimization technique (CMOD-DE) based on DE by Wang and Cai [17], versions of which have been previously applied for other types of electric machines, e.g. [18-21], is specially formulated and applied to SynRel. DE based optimization algorithms were reported to be effective in terms of average time for finding the optimal solution, indicating good potential of 
electrical machine design problems. A recent systematic literature review and numerical benchmark study by Duan and Ionel compared DE with the popular response surface method based optimization and others, and the former was found to be superior when the number of candidate designs is very high [22]. Secondly, computationally efficient FEA previously, proposed by the authors' extended research group for the comprehensive performance evaluation of PM synchronous machines [23, 24], is adapted to SynRel here. This allows for the solution of large scale optimization problems with many independent variables and thousands of candidate machines in the design search space. Thirdly, an unconstrained formulation with three objectives, including power factor and torque ripple is proposed. A third concurrent objective, represented by a new performance index labeled as "badness", which combines torque and losses, is considered. It is shown that this unconstrained formulation leads to a faster convergence of the modified DE technique, as compared with to more commonly used constrained optimization algorithms. And lastly, from an engineering point of view, the large scale optimization studies described in this paper illustrate on a practical case study that although relatively high specific power, and efficiency, and low torque ripple can be achieved through systematic automated design, the relatively low power factor remains a challenge and an inherent natural limitation for this type of electric machine.

The analysis approach that enables the fast processing of thousands of candidate designs is described in the next section of the paper. The third section of the paper covers aspects of robust geometric modeling of the rotor, the mathematical formulations for the optimization objectives, the specification of independent variables, and the flow chart of the DE optimization algorithm. Numerical and experimental studies for a $10 \mathrm{hp} 1,800 \mathrm{rpm}$ rating are described in the last section before conclusions.

\section{ANALYSIS}

The SynRel machine topology studied in the paper is operated from an electronically controlled power electronic controller and does not include a squirrel cage, which would enable line-start and line-fed operation. The system is vectorially controlled according to the generic block diagram depicted in Fig.1, and the current is regulated to a sinewave. The magnitude and the angle of the current in the $d q$ plane is adjusted in order to achieve optimal performance and fully exploit the magnetic reluctance effect that produces the electromagnetic torque. The phasor diagram from Fig.2 follows the conventions specific to non-salient PM machines, such as IPMs [25]. This approach was adopted in order to support a unitary and systematic comparative study between SynRel and PM machines, which will be covered in a future paper. For performance evaluations, including the effect of harmonics, calculations are performed in the $a b c$ reference frame and conversions to and from the $d q$ reference frame are employed. For given sine-wave current and torque angle, the $2 \mathrm{D}$ electromagnetic field distribution in the motor cross section is calculated with FEA as exemplified in Fig. 3.

SynRel motors are known to be highly non-linear due to the strong magnetic saturation and therefore require a substantial effort for accurate analysis. Yet, optimal search algorithms involve the evaluation of thousands of candidate designs and, consequently, call for fast computations.

Unlike previous publications that employed in this respect an equivalent magnetic circuit formulation, e.g. [5], and, in order to make the study possible with state of the art software and hardware technology, a computationally efficient electromagnetic finite element analysis (CE-FEA), which was originally developed for PM brushless AC motors [23], has been extended to accommodate the high harmonic content specific to SynRel topologies. CE-FEA is ultra-fast because it employs only a limited number of magnetostatic solutions, which is dependent on the highest mmf harmonic of interest in the study, and fully exploits the symmetries of synchronous electric machines through space-time transformations, therefore reducing the computational time by at least one order of magnitude, as compared with conventional transient FEA [24].

The electromagnetic CE-FEA was implemented in the scripting language of the ANSYS/Maxwell2D software, which was used as the computational engine for the studies described in the paper. Electromagnetic torque, including ripple, induced voltages, and core losses are all calculated with CE-FEA. For the relatively low speed application of $1,800 \mathrm{rpm}$ considered in the current study, the main limitation of dimensions for flux guides and bridges in the rotor is determined by the high-volume progressive die stamping manufacturing process, which calls for a minimum recommended thickness of approximately twice the lamination thickness. For example, in the current study, the bridges at the top of the rotor were set to a constant value of $1 \mathrm{~mm}$, which ensures a compromise between magnetic saturation/leakage and manufacturability. For higher speed applications, more detailed mechanical calculations, such as FEA for von Mises stress should be considered as part of the design process.

CE - FEA for PM machines has been originally introduced in [23] and [24]. Given that both the PM machine and SynRel are synchronous machines operating based on a rotating magnetic field, CE-FEA is applicable to SynRel motors as well. A main assumption in CE-FEA is that the machine is supplied by quasi-sinusoidal currents, as it is the case if PWM current regulated inverters are employed. The field of the motor is calculated using magnetostatic FEA with the instantaneous motor phase currents and rotor position as inputs. Outputs include the magnetic vector potentials (MVP), which are post-processed to determine: flux linkages, flux densities, back EMFs, torque, and losses. For a symmetric 3phase AC machine under steady state operating conditions, a single magnetostatic solution provides three equidistant points on the flux linkage waveform. Using half wave symmetry, the number of points on the flux linkage waveform can be doubled to 6. Additional points on this waveform can be determined by magnetostatic solutions at other equidistantly spaced rotor positions over one phase belt, and the corresponding values of instantaneous phase currents. Thus, the maximum order of space harmonic $\left(\nu_{m}\right)$ that can be captured depends on the number of magnetostatic solutions (s) and is given by,

$$
\nu_{m}=3 s-1
$$




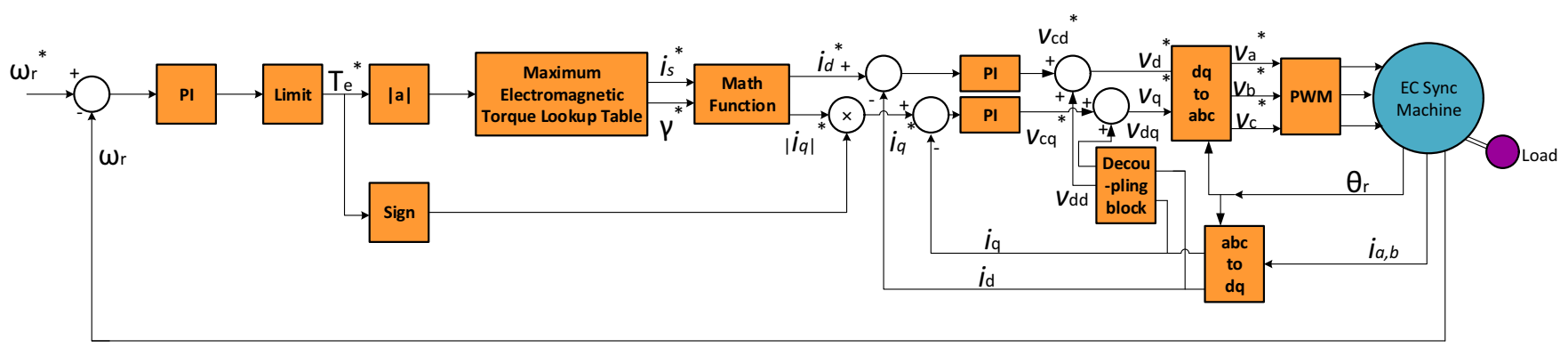

Fig. 1. Generic block control diagram for electronically commutated synchronous reluctance (SynRel) motors.

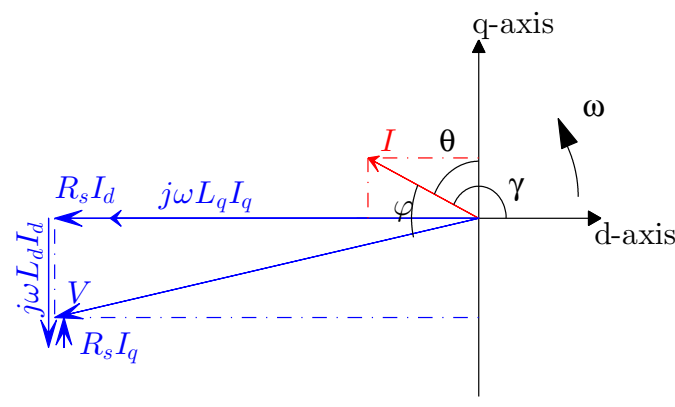

Fig. 2. SyncRel machine phasor diagram in the $d q$ rotor reference frame following the conventions typically used for synchronous salient PM motors.

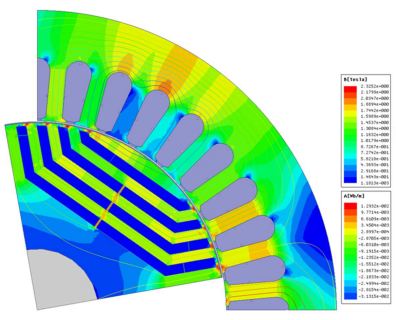

(a)

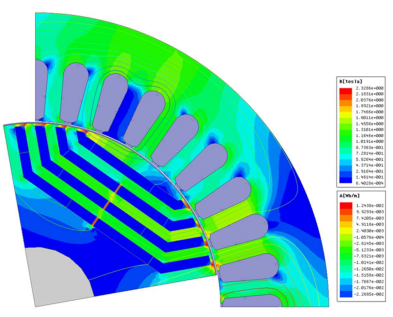

(b)
Fig. 3. Example flux plots in the cross-section of the prototype SynRel motor running at rated current and speed and a torque angle of $135^{\circ}$ (a) and $160^{\circ}$ (b), respectively. Performance is comprehensively evaluated using an ultra-fast computationally efficient electromagnetic finite element (CE-FEA) technique.

Care must be taken in order to ensure that the number of computation points is high enough to capture the most significant harmonic. Table I exemplifies the harmonics of the rated torque, including those computed by time stepped FEA, as illustrated in Fig. 4. As expected for a 36-slot 4pole configuration, the maximum frequency of interest is the $36^{t h}$ harmonic due to the slotting. As shown in the table and waveform, a total of 13 magnetostatic solutions covering 60 deg electrical degrees, i.e. one phase belt, will provide satisfactory calculations, in line with the previous equation. It is recommended that when a new motor configuration is studied, a time-stepping FEA is performed to validate the selection of computational points for CE-FEA. A more general study about the frequency spectrum of the torque ripple, and
TABLE I

TRANSIENT FEA AND CE-FEA CALCULATIONS FOR THE PROTOTYPE SYNREL MOTOR AT RATED CURRENT AND POWER. ONLY THE SIGNIFICANT HARMONICS ARE REPORTED.

\begin{tabular}{c|c|cccc}
\hline Type & Trans & \multicolumn{4}{|c}{ CE-FEA } \\
\hline Points & 181 & 5 & 7 & 13 & 14 \\
\hline Torque & \multicolumn{5}{|c}{ p.u. } \\
\hline Average & 1.000 & 0.990 & 0.996 & 0.994 & 0.994 \\
6th harmonic & 0.014 & 0.069 & 0.010 & 0.015 & 0.014 \\
18th harmonic & 0.065 & N/A & 0.057 & 0.064 & 0.063 \\
36th harmonic & 0.022 & N/A & N/A & 0.024 & 0.022 \\
\hline
\end{tabular}

its variation with the number of stator slots and rotor barriers is reported in for example in [26].

CE-FEA is also used to determine the flux densities in different parts of the magnetic circuit. For this 36-slot machine, each magnetostatic solution would yield radial and tangential flux densities at 18 samples in different locations such as the yoke, yoke-tooth junction, midtooth and tooth-tip, respectivelly, spaced $\theta_{s} / \omega$ seconds apart, where $\theta_{s}$ is the slot pitch, and $\omega$ is the rotor speed. It was previously shown for other synchronous machines that the core losses estimated based on the tooth and yoke flux density variations provide satisfactory results [24].

The magnetostatic calculations performed over 60 electrical degrees include the effect of mmf harmonics on results such as 3-phase voltages, torque ripple, and core losses. Reducing the computational span to only one slot pitch, which is 20 electrical degrees in our example study, would require special provisions or approximations to account for mmf harmonics.

Based on the average electromagnetic torque, $T_{e}$, and corelosses, $W_{F e}$, both of which are calculated by CE-FEA, and copper, $W_{C u}$, and windage and friction losses, $W_{w w f}$, which are estimated analytically, the power balance is described by:

$P_{e}=T_{e} \frac{2 n \pi}{60}, P_{\text {in }}=P_{e}+W_{C u}, P_{\text {out }}=P_{e}-W_{F e}-W_{w w f}$,

where $P_{i n}$ is the input power, $P_{e}$ is the electromagnetic power, $P_{\text {out }}$ is the output (shaft) power, and $n$ is the rotational speed in rpm.

A global performance index, which is based on the electromagnetic torque, $T_{e}$, and total losses, $W_{T}$, is introduced as "badness":

$$
B_{d}=\frac{\sqrt{W_{T}}}{T_{e}}
$$




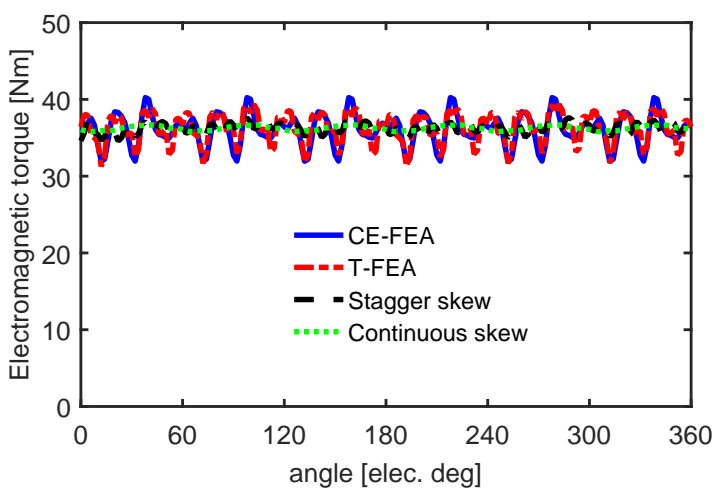

Fig. 4. Electromagnetic torque waveforms for the prototype motor (see Table I). CE-FEA used 13 discrete points. The effect of skew on largely reducing torque ripple is also illustrated.

This "badness", $B_{d}$, is the inverse of the more familiar "goodness", $G_{d}$, and is employed because is more suitable for minimization problems, such as those studied in this paper. The minimization of "badness" can be achieved through the reduction of losses and/or the increase of output torque. Further discussions on "badness" and "goodness" and on their relationships to the torque constant, losses and heat are included later in the paper.

The displacement power factor is calculated as the phase difference between the per-phase fundamental wave of the induced voltage, $v_{p h}$ and of the given current, $i_{p h}$, which is considered to be purely sinusoidal in our analysis of current-regulated electronically controlled SynRels. A power factor that includes the "true rms" of the low-frequency mmf harmonics present in the model is calculated using the real and apparent power:

$$
\mathrm{DPF}=\operatorname{ang}\left(v_{p h}, i_{p h}\right), \quad \cos \varphi=\frac{P_{i n}}{S}=\frac{P_{i n}}{3 V_{p h} I_{p h}} .
$$

Another typical performance index used in the study is the peak-to-peak (max-to-min) torque ripple:

$$
T_{r p k}=\frac{T_{e M}-T_{e m}}{T_{e}}
$$

where $T_{e M}$ and $T_{e m}$ are the maximum and minimum value of the electromagnetic torque, respectively.

It should be noted that the numerical values reported for torque ripple throughout this paper are calculated by $2 \mathrm{D}$ FEA in the motor cross-section. The effect of a stator to rotor relative axial skew can be accounted in post processing through harmonic factors, yet another advantage of CE-FEA, or by adding the contributions of multiple axial sections. For constructions using a single-step axial stagger in the rotor, as the prototype later described, the torque ripple can be calculated on the method described in [27], and is substantially reduced from its 2D FEA calculated value. For the continuous skew, the resultant torque is evaluated as

$$
\begin{gathered}
T(\theta)=\sum_{n=6,18,36 . .} k_{s k} \sin (n \theta) \\
k_{s k}=\frac{\sin \left(n \theta_{s k} / 2\right)}{n \theta_{s k} / 2}
\end{gathered}
$$

where $k_{s k}$ is the skew factor, and $\theta_{s k}$ is the skew angle. For the example shown in Fig. 4, the torque ripple without skew is $22 \%$, while with the single step axial stagger skew it reduces to $8.5 \%$ and to just $2.4 \%$ with continuous skew.

\section{OPTIMIZATION}

The 4-pole rotor considered in the study employs a lamination with four flux barriers as shown in Fig. 5. The rotor pole pitch $\left(\alpha_{p}\right)$ and the radius of the barrier top center $\left(R_{c}\right)$ are considered constant in the study. Nine (9) rotor geometrical ratios: $K b, K b t, K b 4, K b 3, K b 2, K b 1, K t 3, K t 2$, and $K t 1$, were considered as independent variables for a robust parametric model that avoids the overlapping of geometrical entities during the automated design optimization procedure and produces different designs as exemplified in Fig. 6. The SynRel rotor geometry can be constructed completely as a function of these independent variables. The geometrical ratios are defined as follows:

1) Kbt: the ratio of the total length of the barriers and flux tubes to the maximum total length

2) $K b$ : the ratio of the total barrier thicknesses to the total length of the flux barriers and tubes,

3) $K b 1$ : the ratio of the thicknesses of the first barrier to the total barrier thicknesses

4) $K b 2$ : the ratio of the thicknesses of the second barrier to the total barrier thicknesses of the second, third and fourth barrier

5) $K b 3$ : the ratio of the thicknesses of the third barrier to the total barrier thicknesses of the third and fourth barrier

6) Kb4: the ratio of the thicknesses of the fourth barrier to the sum of the fourth barrier thickness and tube width

7) $K t 1$ : the ratio of the first flux tube width to the total tube width

8) Kt2: the ratio of the second flux tube width to the total width of the second, third and fourth flux tube

9) $K t 3$ : the ratio of the third flux tube width to the total width of the third and fourth flux tube

Auxiliary calculated geometric variables and expressions can be deduced based on the input geometric variables, For instance, the width of the fourth barrier, $h c 4$, is calculated based on $K b 4$ as:

$h c 4=(L b t-h c 1 / 2-h c 2-h c 3-W t 1-W t 2-W t 3) \cdot K b 4$,

where $L b t$ is the total distance from point 4 from the bridge of the top flux barrier to the interpolar axis,

$L b t=h c 1 / 2+h c 2+h c 3+h c 4+W t 1+W t 2+W t 3+W t 4$,

and $h c 1, h c 2, h c 3$ are the widths of the first, second and third barrier, respectively; $W t 1, W t 2, W t 3$ are the widths of the first, second and third flux tube, respectively. Similarly, the width of the third barrier is defined using the ratio $K b 3$ as:

$$
h c 3=(h c t-h c 1 / 2-h c 2) \cdot K b 3
$$




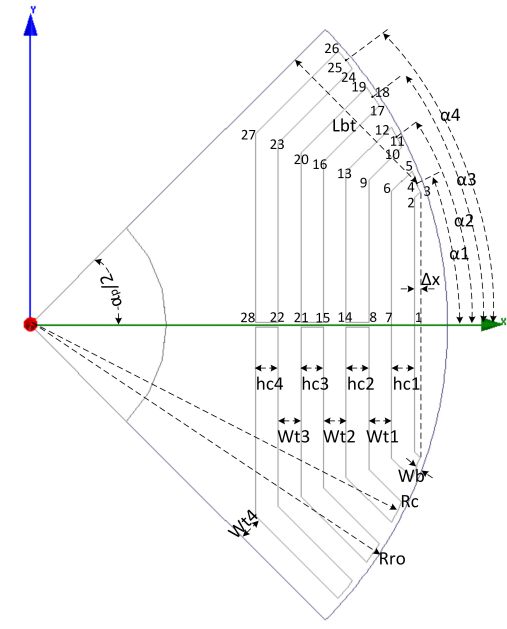

Fig. 5. Geometry for the parametric SynRel rotor model with four (4) flux barriers and nine (9) independent variables.

The angular position of the first barrier at the airgap can be calculated as,

$$
\begin{gathered}
\alpha_{1}=\alpha_{p} / 2- \\
\arcsin \left(\frac{W t 4+W t 3+W t 2+W t 1+h c 4+h c 3+h c 2+\frac{h c 1}{2}}{R c}\right)
\end{gathered}
$$

In addition to these geometrical ratios, $\Delta X$, a factor which accounts for how deep the barriers are positioned radially is also considered as an independent variable. The $x-y$ coordinates defining the outlines of the SynRel geometry are found out as functions of these parameters. The upper and lower limits of the geometric parameters are provided in Table II. The DE algorithm designed by the authors, was implemented using MATLAB.

TABLE II

UPPER AND LOWER LIMITS OF GEOMETRICAL PARAMETERS CONSIDERED IN THE STUDY.

\begin{tabular}{c|cc}
\hline Parameter & Lower limit & Upper limit \\
\hline$\Delta \mathrm{X}$ & 0.8 & 1.2 \\
$\mathrm{~Kb}$ & 0.48 & 0.72 \\
$\mathrm{~Kb} 4$ & 0.38 & 0.57 \\
$\mathrm{~Kb} 3$ & 0.26 & 0.39 \\
$\mathrm{~Kb} 2$ & 0.20 & 0.30 \\
$\mathrm{Kt} 3$ & 0.78 & 1.16 \\
$\mathrm{Kt} 2$ & 0.39 & 0.59 \\
$\mathrm{Kt} 1$ & 0.26 & 0.40 \\
$\mathrm{~Kb} 1$ & 0.09 & 0.13 \\
$\mathrm{Kbt}$ & 0.47 & 0.71 \\
TAng & 140 & 165 \\
\hline
\end{tabular}

In order to minimize the computational effort, the torque angle (TAng) is also considered as an independent variable following a proposal initially described in another publication [6]. The current paper brings further contributions by clearly illustrating the fact that such an approach is feasible for largescale studies and that the torque angle also evolves towards an optimal value.

In the optimization study, the stator lamination and the length of the core stack are kept unchanged from those of

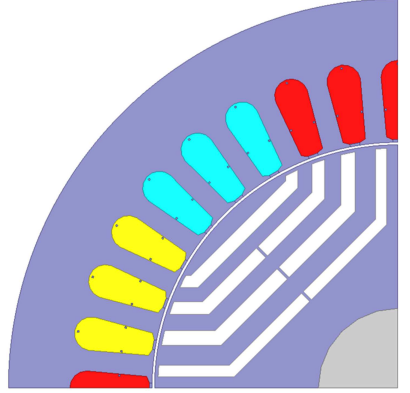

(a) Design 4863

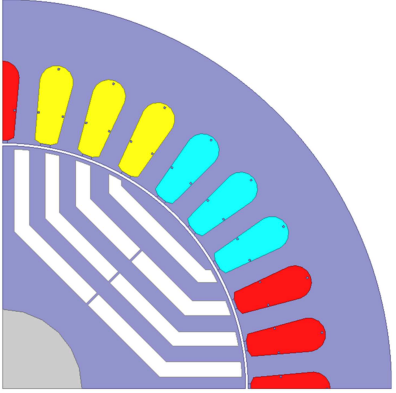

(b) Design 2165
Fig. 6. Motor cross-section for example optimal designs for Problem A (a) and Problem B (b), respectively.

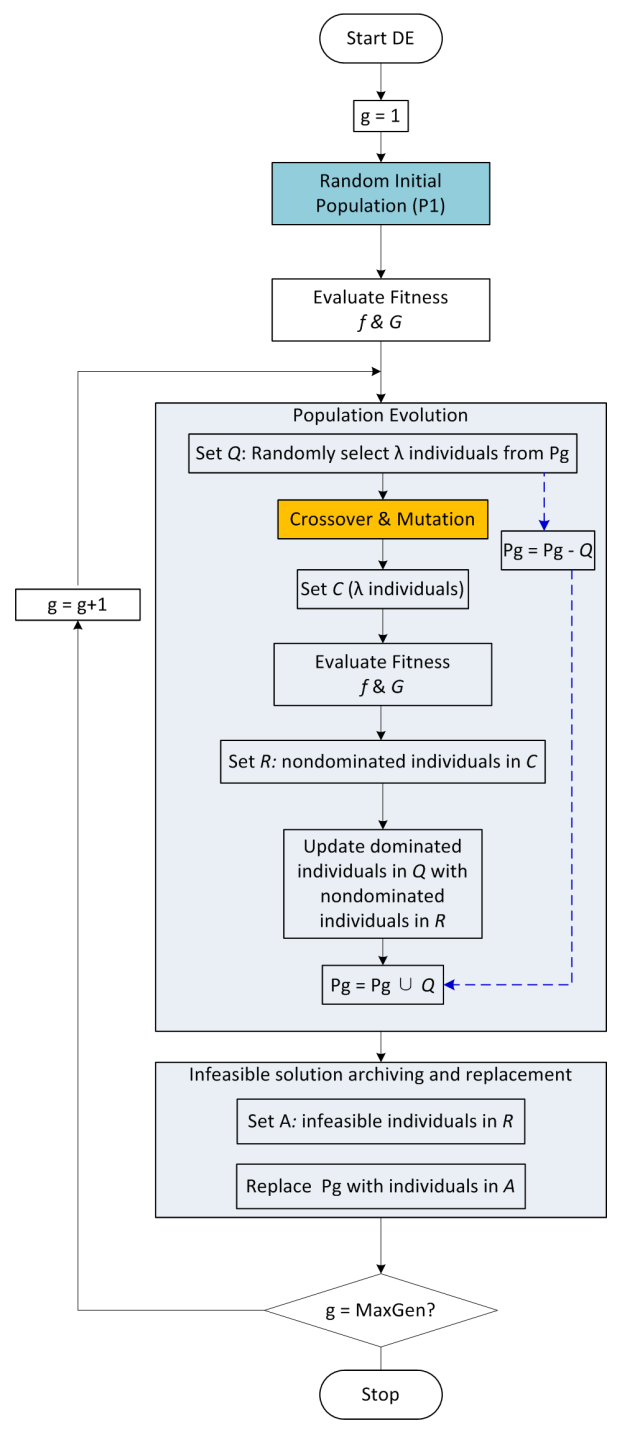

Fig. 7. Flow chart of the proposed CMODE optimization algorithm based on the differential evolution (DE) method. 
a 10hp 4-pole induction motor. The optimization study and the FE calculations are performed for a fixed rated speed of 1,800 rpm. The winding pattern, slot fill, and the current density are also kept invariable, and the number of turns may be adjusted to fit the power electronics supply voltage. This approach ensures that all the designs studied have the same cost although they may have different output performance, including different output power. Two multi-objective optimization formulations have been independently studied.

The first optimization problem, $(A)$, employs two concurrent objectives of minimum "badness" and minimum torque ripple and a single constraint for a minimum power factor of 0.7 , which is considered to be still acceptable in comparison with a state-of-the-art induction motor with the same rating:

$$
\min \left(B_{d}\right), \min \left(T_{r p k}\right), \text { and } \cos \varphi>0.7 .
$$

The second optimization problem, $(B)$, is an untypical unconstrained minimization formulation with three (3) concurrent objectives for "badness" and torque ripple and changed sign (CS) power factor:

$$
\min \left(B_{d}\right), \min \left(T_{r p k}\right), \text { and } \min (-\cos \varphi) .
$$

The optimal search algorithm, which is schematically depicted in Fig. 7, involves multiple generations, each with many individuals. This requires the performance evaluation of thousands of candidate designs using electromagnetic CEFEA. To further expedite the process, the ANSYS/Maxwell software, which was employed as a computational engine, was used together with its multi-core distributed solve option (DSO). The optimization procedure developed is based on the modified multi-objective differential evolution (CMODE) algorithm proposed by Wang and Cai [17].

\section{NUMERICAL AND EXPERIMENTAL STUDY}

The results shown in Figs. 8 - 11 for Problem $A$ and Problem $B$ were obtained by employing 51 generations in the CMODE optimization, each with 100 individuals/designs, yielding a total number of 5,100 candidate designs for each large-scale problem. The solution of multi-objective problems provides not one/single best design, but rather a family of "best compromise designs", represented by a Pareto-front as exemplified in the figures.

The scatter plots indicate that the results for the two distinct optimization problems are comparable to a large extent. In line with expectations, the optimization evolves towards designs with relatively high output power, low badness, and high efficiency. These designs operate at a torque angle of approx. $150^{\circ}$ and relatively low torque ripple can be achieved, even without a relative rotor to stator axial skew, through the automated optimization of the rotor geometry.

From the Pareto-fronts, two designs with high power output and power factor, i.e. 4863 and 2165 (see also Fig. 6) have been selected and their performance was compared in more detail in Table III. Other design IDs on the Pareto front, for example those with lower torque ripple could as well have been selected, but would have lower values of power factor or higher badness. Values are reported for two different operating conditions - maximum power and maximum power factor. In each case, the number of turns is selected in order to match the inverter supply conditions and the available DC bus voltage, keeping the ampere turns and current density fixed.

One advantage of the unconstrained Problem B over the more conventional constrained formulation from Problem A is that it converges faster. For Problem B, a "best compromise" was found sooner, in the 22-nd generation out of 51. This is evidenced by the sequential ID of the designs. Further advantages of Problem B, in terms of faster convergence and superior design performance, badness, power factor and torque ripple, are illustrated in Figs.12 and 13 that summarize results for the Pareto front designs. The shaft torque for all the Pareto designs is within plus or minus $1 \%$ of the rated $40 \mathrm{Nm}$. It should be noted that by mathematical definition, a Pareto front only includes the designs for which improvement in one objective can be achieved by allowing a deterioration in another objective. As such, the number of designs in the Pareto is rather small, 9 and 10 for the two problems, respectively. Figures 12 and 13 also illustrate the fact that design objectives are typically conflicting and as such, for example, designs with low "badness" may have high torque ripple, while the relatively low power factor remains a major challenge of SynRel technology.

The distribution of the design parameters, i.e. independent variables, for the motor designs from the the Pareto-fronts for Problems A and B are plotted in Fig. 14 in p.u. and the actual values of the parameters are listed in Tables IV and V. This combination of parameters yields "best compromise" or "good" machine designs.

The optimization results also illustrate the inherent limitations for SynRel technology in terms of relatively low power factor. It should be noted that many of the early studies, which spurred the technology development years ago, were based on models that assumed that designs with high saliency can be realized, and ignored magnetic saturation and core losses, while in fact these typically have significant effects.

With reference to Fig. 2 the $d q$ voltage components can be calculated as a function of the $d q$ current components,

$$
\left\{\begin{array}{l}
V_{d}=R_{p h} I_{d}-\omega L_{q} I_{q}=V_{p h} \sin \left(\theta_{0}+\varphi\right) \\
V_{q}=R_{p h} I_{q}+\omega L_{d} I_{d}=V_{p h} \cos \left(\theta_{0}+\varphi\right)
\end{array},\right.
$$

where $R_{p h}$ is the winding phase resistance, and $\omega$ is the electrical rotating speed (angular frequency) in elec.rad/s. The induced terminal phase voltage, $V_{p h}$, and the power factor angle, $\varphi$, are calculated by CE-FEA. Solving for the $d q$ inductances,

$$
\left\{\begin{array}{l}
L_{d}=\left(-R_{p h} I_{q}+V_{q}\right) / \omega / I_{d} \\
L_{q}=\left(R_{p h} I_{d}-V_{d}\right) / \omega / I_{q}
\end{array},\right.
$$

the saliency ratio, i.e. $L_{q} / L_{d}$ can be estimated under the specific non-linear operating conditions. As shown in Figs. 8 and 11 for the Pareto front designs the values are in a typical range of 5-7.

For a current excited machine such as SynRel, the magnetic field is non-linearly proportional to the current. The core losses are non-linear proportional to the square of the flux 


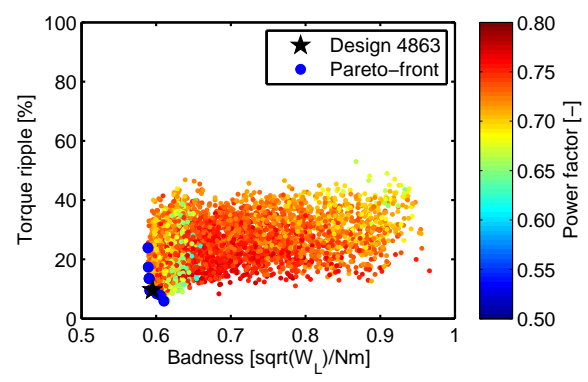

(a) power factor

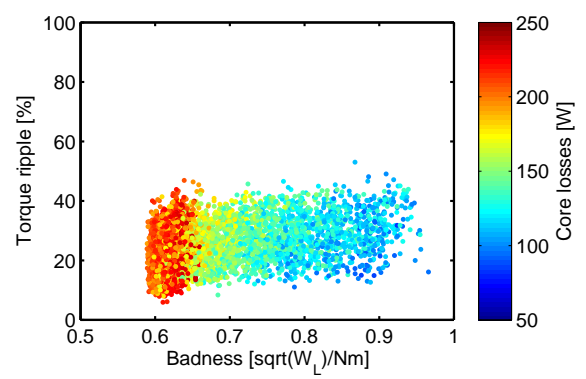

(d) core losses

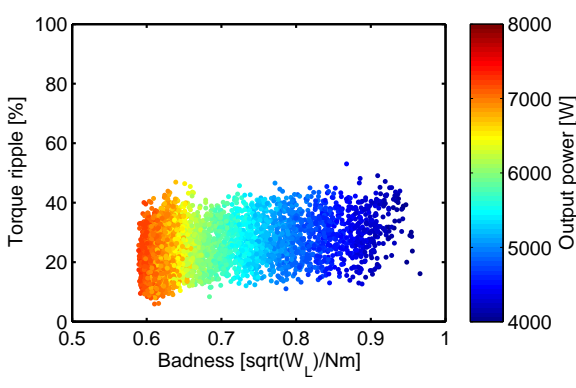

(b) output power

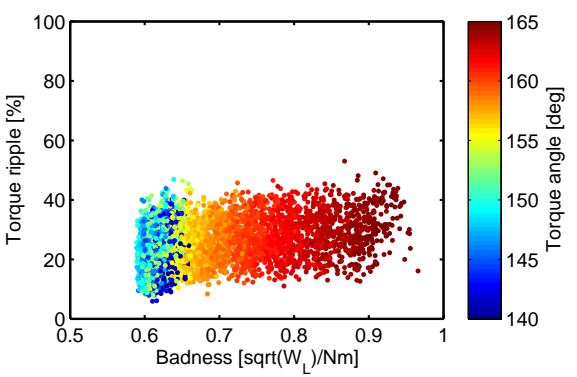

(e) torque ripple

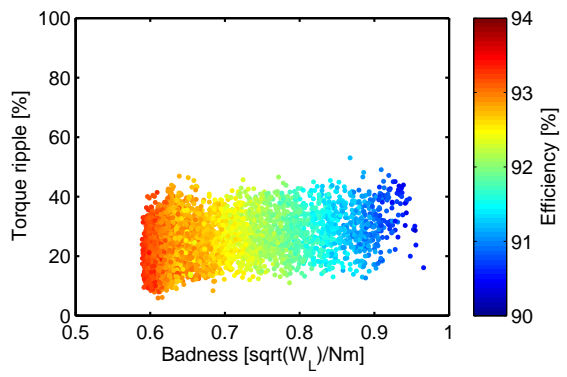

(c) efficiency

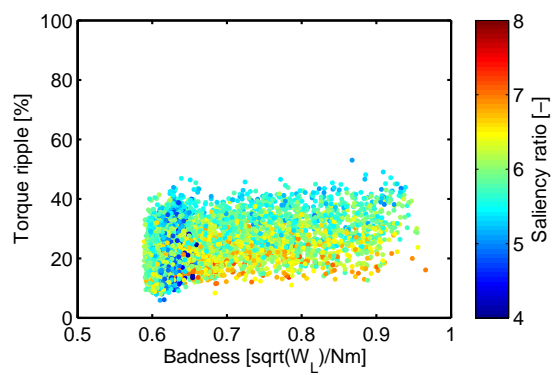

(f) saliency ratio

Fig. 8. Scatter plot showing the values of objectives functions (torque ripple and "badness") for all the designs considered in the constrained optimization Problem A with values of other parameters indicated by a color scale.

TABLE III

PERFORMANCE COMPARISON OF TWO OPTIMAL DESIGNS: 4863 FROM THE CONSTRAINED PROBLEM A WITH TWO OBJECTIVES AND 2165 FROM THE UNCONSTRAINED PROBLEM B WITH THREE OBJECTIVES.

\begin{tabular}{cccccccccccc}
\hline $\begin{array}{c}\text { Opt. } \\
\text { Type }\end{array}$ & $\begin{array}{c}\text { Design } \\
\text { ID }\end{array}$ & $\begin{array}{c}\text { Badness } \\
\left.\sqrt{W_{L}}\right]\end{array}$ & $\begin{array}{c}\text { Power } \\
\text { Factor } \\
{[-]}\end{array}$ & $\begin{array}{c}\text { Torque } \\
\text { Ripple } \\
{[\%]}\end{array}$ & $\begin{array}{c}\text { Torque } \\
{[\mathrm{Nm}]}\end{array}$ & $\begin{array}{c}\text { Torque } \\
\text { Angle } \\
{[\mathrm{Deg}]}\end{array}$ & $\begin{array}{c}\text { EM } \\
\text { Power } \\
{[\mathrm{W}]}\end{array}$ & $\begin{array}{c}\text { EM } \\
\text { Eff. } \\
{[\%]}\end{array}$ & $\begin{array}{c}\text { Turns } \\
{[-]}\end{array}$ & $\begin{array}{c}\text { Current } \\
{[\mathrm{A}]}\end{array}$ & $\begin{array}{c}\text { Induced } \\
\text { Voltage } \\
{[\mathrm{V}]}\end{array}$ \\
\hline A & 4863 & 0.58 & 0.714 & 9.2 & 40.0 & 147.5 & 7320.8 & 93.2 & 21 & 15.0 & 245.7 \\
B & 2165 & 0.57 & 0.722 & 10.1 & 40.2 & 147.5 & 7368.3 & 93.3 & 21 & 15.0 & 245.7 \\
\hline \multicolumn{10}{c}{ Performance at } & maximum & output electromagnetic power \\
\hline A & 4863 & 0.64 & 0.761 & 11.9 & 33.6 & 157.5 & 6192.8 & 93.0 & 26 & 12.1 & 241.8 \\
B & 2165 & 0.60 & 0.767 & 12.4 & 33.4 & 157.5 & 6161.3 & 93.1 & 27 & 11.6 & 248.4 \\
\hline
\end{tabular}

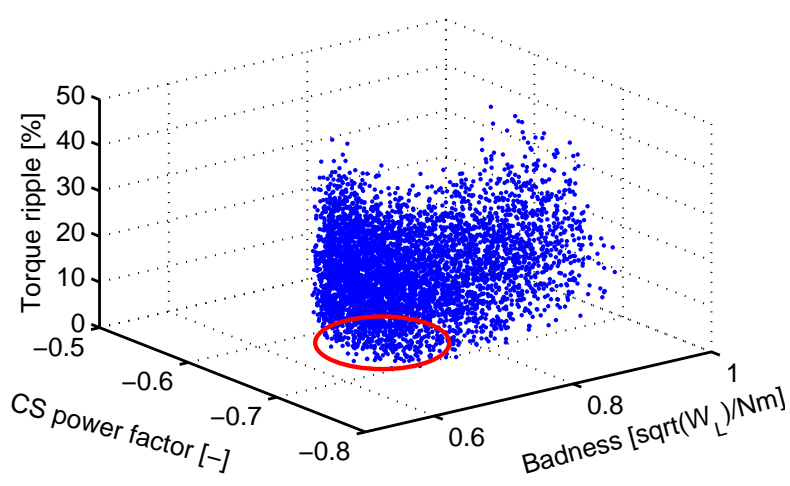

Fig. 9. Scatter plot and Pareto 3D region (marked with the ellipse) for the unconstrained optimization Problem $B$ with three concurrent objectives.

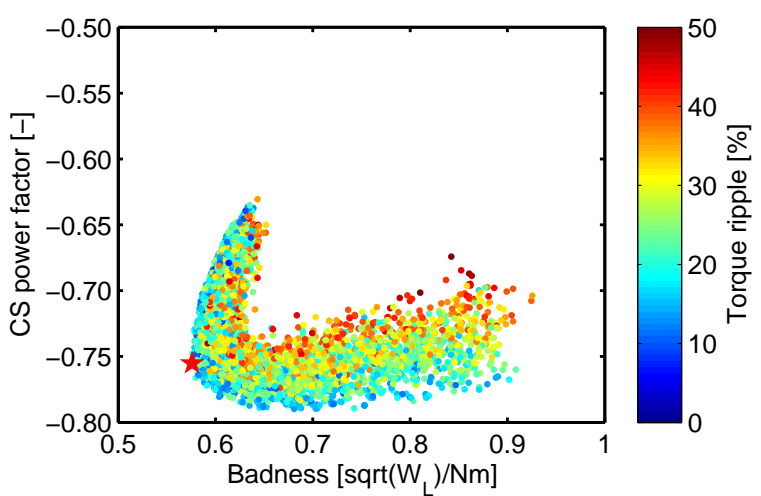

Fig. 10. To illustrate for Problem $B$ the profile typical to a minimization problem, the power factor is plotted with changed sign (CS). 


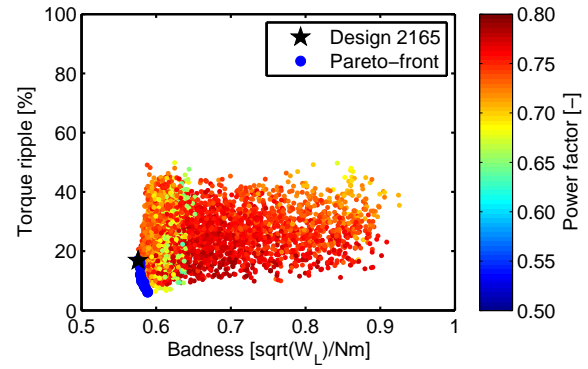

(a) power factor

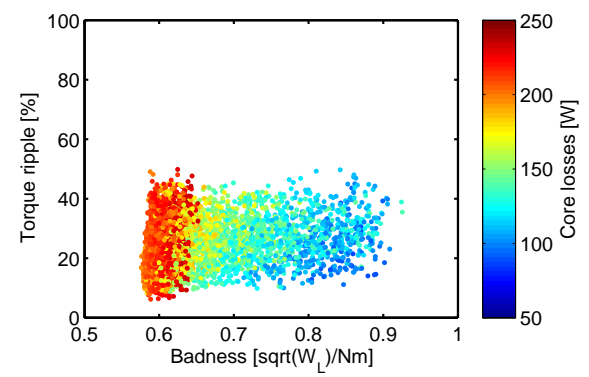

(d) core losses

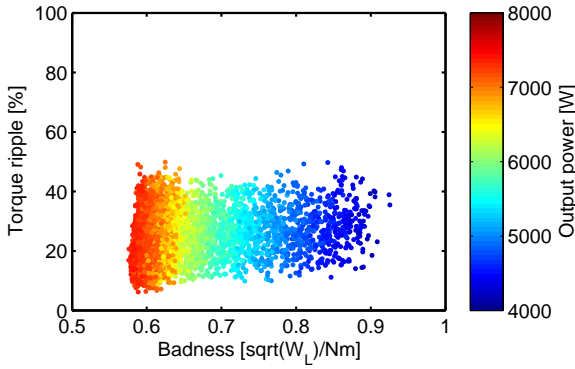

(b) output power

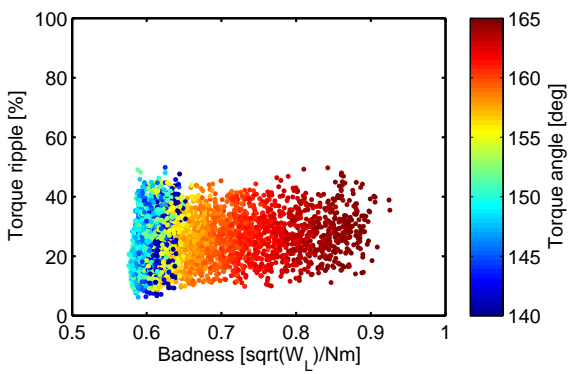

(e) torque ripple

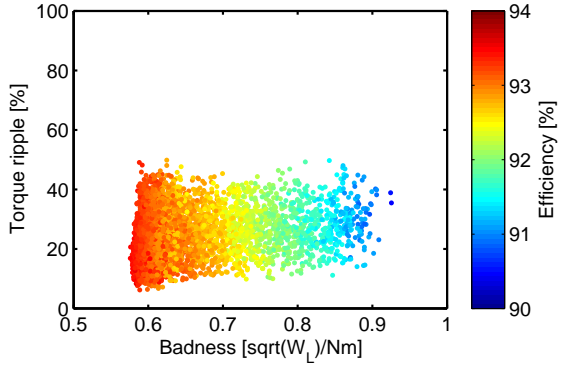

(c) efficiency

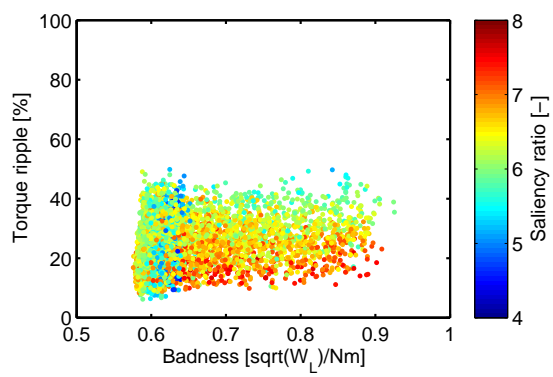

(f) saliency ratio

Fig. 11. Scatter plot showing the values of objectives functions (torque ripple and "badness") for all the designs considered in the unconstrained optimization Problem B with values of other parameters indicated by a color scale.

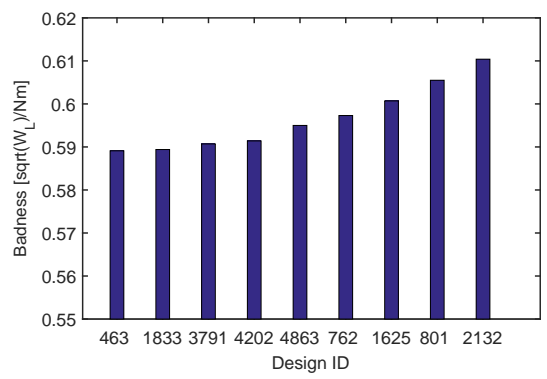

(a)

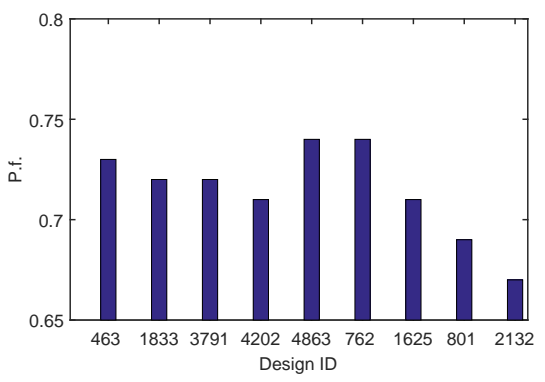

(b)

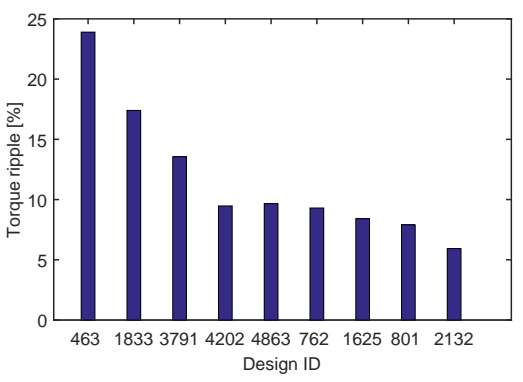

(c)

Fig. 12. Values of optimization objectives: badness and torque ripple, and constrained power factor for the designs from the Pareto front of problem A.

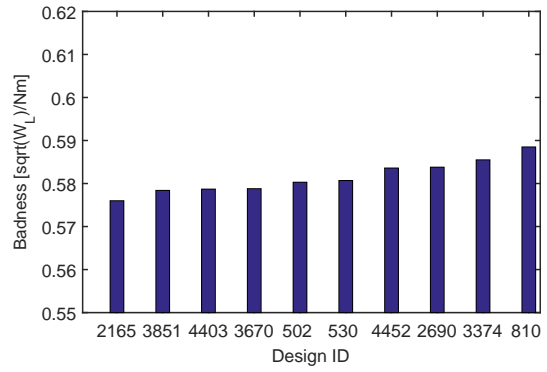

(a)

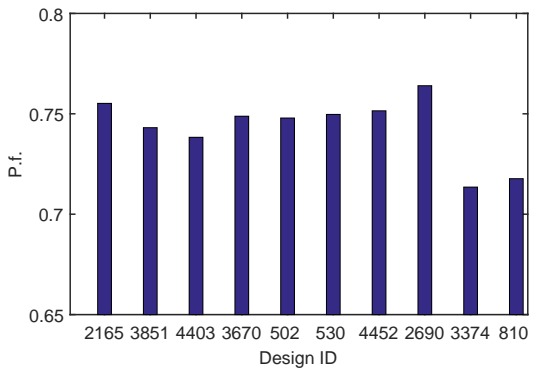

(b)

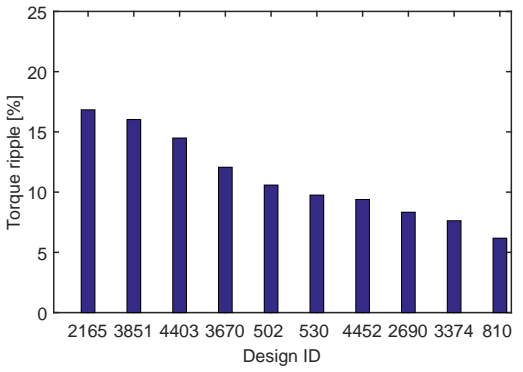

(c)

Fig. 13. Values of optimization objectives: badness, power factor and torque ripple for the designs from the Pareto front of the unconstrained problem B 


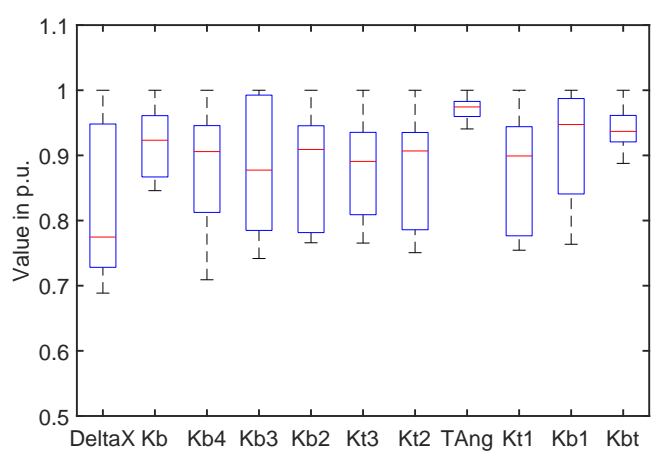

(a) Problem A

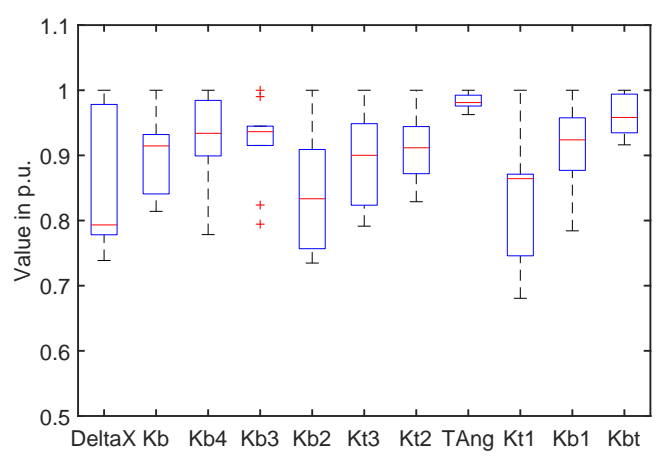

(b) Problem B

Fig. 14. The distribution of the independent design variables for the designs from the Pareto-fronts shown on a box plot for (a) Problem A and (b) Problem B. The red line represents the median of the data and the width of the box is the interquartile range. Data points outside 1.5 times the interquartile range are outliers and represented by ' + '

TABLE IV

THE VARIATION OF THE INDEPENDENT VARIABLES FOR THE DESIGNS ON THE PARETO-FRONT IN PROBLEM A

\begin{tabular}{cccc}
\hline Parameter & Minimum & Average & Maximum \\
\hline$\Delta X$ & 0.82 & 0.98 & 1.19 \\
$\mathrm{~Kb}$ & 0.50 & 0.55 & 0.59 \\
$\mathrm{~Kb} 4$ & 0.40 & 0.50 & 0.56 \\
$\mathrm{Kb3}$ & 0.29 & 0.34 & 0.39 \\
$\mathrm{~Kb} 2$ & 0.21 & 0.24 & 0.28 \\
$\mathrm{Kt3}$ & 0.86 & 1.00 & 1.13 \\
$\mathrm{Kt} 2$ & 0.42 & 0.50 & 0.57 \\
$\mathrm{Kt1}$ & 0.27 & 0.31 & 0.35 \\
$\mathrm{~Kb} 1$ & 0.09 & 0.11 & 0.12 \\
$\mathrm{Kbt}$ & 0.63 & 0.66 & 0.71 \\
TAng & 142.59 & 147.34 & 151.59 \\
\hline
\end{tabular}

TABLE V

THE VARIATION OF THE INDEPENDENT VARIABLES FOR THE DESIGNS ON THE PARETO-FRONT IN PROBLEM B

\begin{tabular}{cccc}
\hline Parameter & Minimum & Average & Maximum \\
\hline$\Delta X$ & 0.82 & 0.94 & 1.12 \\
$\mathrm{~Kb}$ & 0.48 & 0.54 & 0.60 \\
$\mathrm{~Kb} 4$ & 0.44 & 0.52 & 0.57 \\
$\mathrm{Kb3}$ & 0.36 & 0.31 & 0.39 \\
$\mathrm{~Kb} 2$ & 0.22 & 0.25 & 0.29 \\
$\mathrm{~K} 33$ & 0.91 & 1.03 & 1.15 \\
$\mathrm{Kt} 2$ & 0.48 & 0.53 & 0.58 \\
$\mathrm{Kt1}$ & 0.27 & 0.33 & 0.39 \\
$\mathrm{~Kb} 1$ & 0.10 & 0.11 & 0.12 \\
$\mathrm{Kbt}$ & 0.65 & 0.68 & 0.72 \\
TAng & 146.80 & 149.70 & 152.50 \\
\hline
\end{tabular}

density, and hence to the current squared. Also, copper losses are proportional to the the current squared, meaning that if the relatively small friction and windage loss component is neglected, losses can be modeled through an equivalent phase resistance $R_{e c}$, such that the inverse of "badness", i.e. "goodness" is:

$$
G_{d}=\frac{1}{B_{d}}=\frac{T_{e}}{\sqrt{W_{T}}}=\frac{T_{e}}{\sqrt{R_{e c}} I^{2}}=\frac{k_{T e}}{\sqrt{R_{e c}}},
$$

where $k_{T e}$ is the electromagnetic torque constant. The last

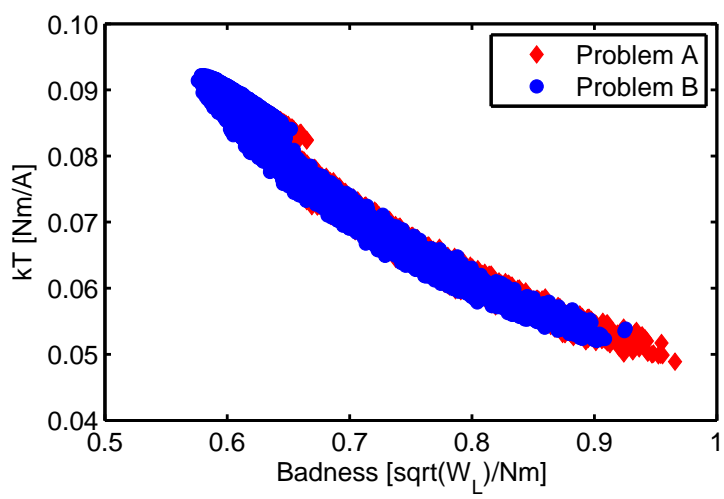

Fig. 15. Electromagnetic torque constant $k_{T e}$ (3) vs. "badness" $B_{d}$ (2).

term in the above equation is very similar to the traditional DC "motor constant" that relates the torque production to the heat dissipated, which in turn is proportional to losses. It is to be noted that the equivalent resistance $R_{e c}$ was not employed in the performance estimations, which were part of the optimization study, and that all the calculations were based on computation of the actual power loss.

Also interesting to note is that the results of these large-scale optimal SynRel motor design studies show that the torque constant and the badness are well correlated (see (15) and Fig. 15).

To serve as a design reference and validation tool a conventional SynRel rotor with equal width flux barriers and guides has been prototyped (Fig. 16). The prototype machine has 4 poles, is built in the NEMA 286 frame, and is rated for 10 $\mathrm{hp}$ at $1,800 \mathrm{rpm}$. The stator to rotor split ratio is represented to scale in Fig. 6. The stator core, which has 36 slots, is the same as that of a production induction motor in the same frame and rating. The modified winding employed approximately the same slot fill as the induction motor and 21 turns per coil. The prototype rotor has an axial single-step stagger skew in order to reduce the torque ripple to a value less than that obtainable by optimization of the rotor geometry. Based on the practical experience of the authors, such stagger skewing would reduce 


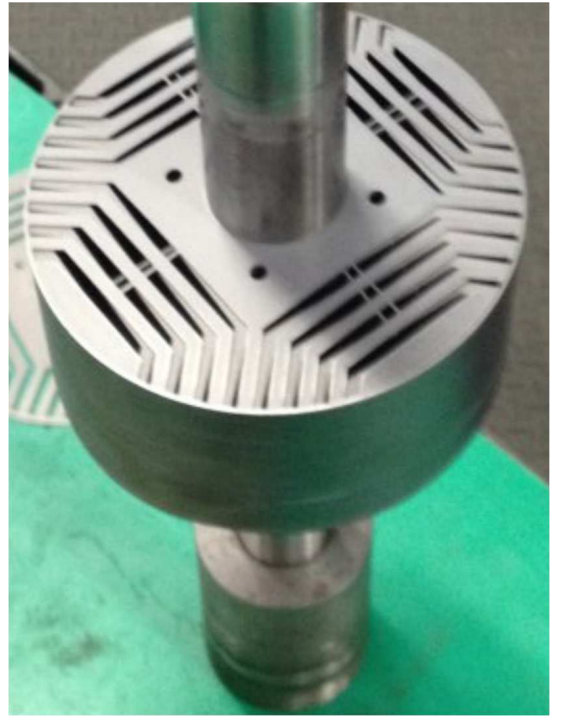

Fig. 16. Prototype rotor during manufacturing; the axial modular stagger skew further reduces the torque ripple from the 2D CE-FEA calculated values reported in other figures.

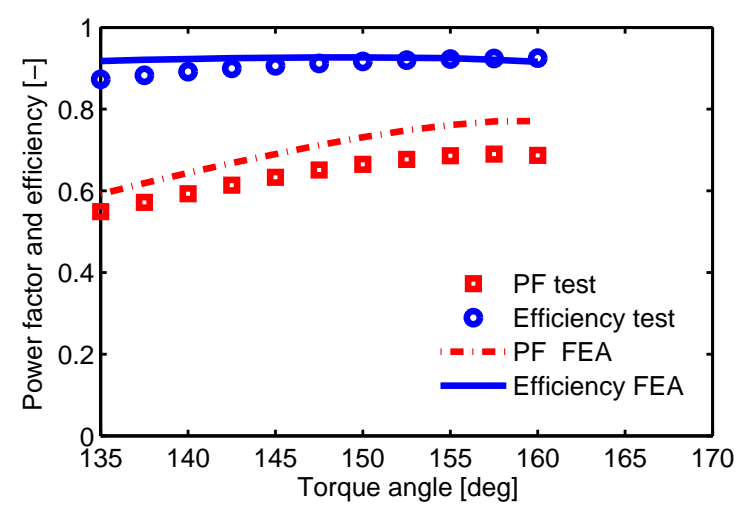

Fig. 17. Example of computational and experimental validation for the prototype motor operating at rated current and rated speed. The torque angle was varied by means of electronic vector control. The efficiency values are reported on a maximum unity scale.

the torque ripple to approximately one third of its unskewed value. This is also verified by calculations in Section II.

The main purpose of the prototyping was to validate the accuracy of CE-FEA, which is the analysis tool that is repeatedly used by the optimization. Systematic simulations with conventional transient FEA and with 13 discrete solutions for CE-FEA have shown very good agreement for all performance indices, as illustrated for example in Table I for the electromagnetic torque. Furthermore, CE-FEA has the advantage of being one order of magnitude faster. Satisfactory agreement between experiments and simulations using CE-FEA was also noted, as illustrated in Fig. 17.

\section{CONCLUSION}

This paper introduced new methods for the automated design optimization of SynRel motors, based on a special computational efficient (CE) electromagnetic FEA. Satisfactory validation was provided using the substantially more time consuming conventional transient FEA and experimental results from a prototype motor. The large scale DE optimization study for a $10 \mathrm{hp} \mathrm{1,800} \mathrm{rating} \mathrm{included} \mathrm{more} \mathrm{than} \mathrm{5,000} \mathrm{candidate}$ designs for each of the two problems studied: one constrained with two concurrent objectives and one unconstrained with three concurrent objectives of "badness", which is a combined performance index for output power and losses, torque ripple, and power factor, respectively.

The unconstrained formulation showed superiority both in terms of faster convergence as well as better design performance. From a practical engineering point of view, it is interesting to note that the results show that while with the new algorithm performance improvements can be achieved in many aspects, the SynRel have a natural inherent limitation in terms of a relatively low power factor.

\section{ACKNOWLEDGEMENTS}

The sponsorship provided to the group at University of Wisconsin - Milwaukee by Regal Beloit Corp., ANSYS, Inc., and Motor Design, Ltd. is gratefully acknowledged.

\section{REFERENCES}

[1] D. A. Staton, TJE Miller, and S. E. Woods, "Maximizing the saliency ratio of the synchronous reluctance motor," Proc. IEE Elect. Power Appl., vol. 140, no. 4, pp. 249-259, 1993.

[2] I. Boldea, Z. X. Fu, and S. Nasar, "Performance evaluation of axially-laminated anisotropic (ala) rotor reluctance synchronous motors," in IEEE Industry Applications Society Annual Meeting, Oct. 1992, Vol. 1, pp. 212-218.

[3] R. Moghaddam, F. Magnussen and C. Sadarangani, "Theoretical and experimental reevaluation of synchronous reluctance machine," IEEE Transactions on Industrial Electronics, vol. 57, no. 1, pp. 6-13, Jan. 2010.

[4] M. J. Kamper, F. S. V. der Merwe, and S. Williamson, "Direct finite element design optimisation of the cageless reluctance synchronous machine," IEEE Transactions on Energy Conversion, vol. 11, no. 3, pp. 547-555, Sep 1996.

[5] J. Baek, M. Rahimian, and H. Toliyat, "Optimal design of pm assisted synchronous reluctance generators using lumped parameter model and differential evolution strategy," in IEEE Energy Conversion Congress and Exposition, Sept. 2009, pp. 2453-2459.

[6] F. Cupertino, G. Pellegrino, and C. Gerada, "Design of synchronous reluctance machines with multi-objective optimization algorithms," in IEEE Energy Conversion Congress and Exposition, Sept. 2013, pp. 1858-1865.

[7] M. Gamba, G. Pellegrino, and F. Cupertino, "Optimal number of rotor parameters for the automatic design of synchronous reluctance machines," in International Conference on Electrical Machines, Sept 2014, pp. 1334-1340.

[8] E. Howard, M. Kamper, and S. Gerber, "Flux barrier and design optimisation of reluctance synchronous machines," in International Conference on Electrical Machines (ICEM), Sept. 2014, pp. 1186-1192.

[9] E. Howard, M. J. Kamper, and S. Gerber, "Asymmetric flux barrier and skew design optimization of reluctance synchronous machines," IEEE Transactions on Industry Applications, vol. 51, no. 5, pp. 3751-3760, Sept 2015.

[10] N. Bianchi, M. Degano, and E. Fornasiero, "Sensitivity analysis of torque ripple reduction of synchronous reluctance and interior pm motors," IEEE Transactions on Industry Applications, vol. 51, no. 1, pp. 187-195, Jan 2015.

[11] S. Guenther and W. Hofmann, "Multi-objective tradeoffs in the design optimization of synchronous reluctance machines 
for electric vehicle application," in IEEE International Electric Machines Drives Conference, May 2015, pp. 1715-1721.

[12] A. T. Loubser and M. J. Kamper, "Design optimisation of reluctance synchronous machine for drive system efficiency," in IEEE Workshop on Electrical Machines Design, Control and Diagnosis (WEMDCD), March 2015, pp. 60-65.

[13] E. Howard and M. Kamper, "Weighted factor multi-objective design optimisation of a reluctance synchronous machine," IEEE Transactions on Industry Applications, vol. PP, no. 99, pp. 1-1, 2016.

[14] S. Sato, T. Sato, and H. Igarashi, "Topology optimization of synchronous reluctance motor using normalized gaussian network," IEEE Transactions on Magnetics, vol. 51, no. 3, pp. 1-4, March 2015.

[15] M. H. Mohammadi, T. Rahman, R. Silva, M. Li, and D. A. Lowther, "A computationally efficient algorithm for rotor design optimization of synchronous reluctance machines," IEEE Transactions on Magnetics, vol. 52, no. 3, pp. 1-4, March 2016.

[16] Y. Wang, D. M. Ionel, M. Jiang, and S. Stretz, "Large scale optimization of electronically controlled synchronous reluctance machines using ce-fea and differential evolution," in IEEE International Electric Machines Drives Conference, May 2015, pp. 1702-1708.

[17] Y. Wang and Z. Cai, "Combining multiobjective optimization with differential evolution to solve constrained optimization problems," IEEE Transactions on Evolutionary Computation, vol. 16, no. 1, pp. 117-134, Feb. 2012.

[18] W. Jiang, T. M. Jahns, T. A. Lipo, W. Taylor, and Y. Suziki, "Machine design optimization based on finite element analysis in a high-throughput computing environment," in IEEE Energy Conversion Congress and Exposition, Sept. 2012, pp. 869-876.

[19] P. Zhang, G. Y. Sizov, D. M. Ionel, and N. A. O. Demerdash, "Design optimization of spoke-type ferrite magnet machines by combined design of experiments and differential evolution algorithms," in Electric Machines Drives Conference (IEMDC),

[26] M. Palmieri, M. Perta, F. Cupertino, and G. Pellegrino, "Effect of the numbers of slots and barriers on the optimal design of synchronous reluctance machines," in International Conference
2013 IEEE International, May 2013, pp. 892-898.

[20] P. Zhang, G. Y. Sizov, M. Li, D. M. Ionel, N. A. O. Demerdash, S. J. Stretz, and A. W. Yeadon, "Multi-objective tradeoffs in the design optimization of a brushless permanent-magnet machine with fractional-slot concentrated windings," IEEE Transactions on Industry Applications, vol. 50, no. 5, pp. 3285-3294, Sept 2014.

[21] Peng Zhang, D. M. Ionel, and N. Demerdash, "Morphing parametric modeling and design optimization of spoke and v-type permanent magnet machines by combined design of experiments and differential evolution algorithms," in IEEE Energy Conversion Congress and Exposition,, Sept. 2013, pp. 5056-5063.

[22] Y. Duan and D. M. Ionel, "A review of recent developments in electrical machine design optimization methods with a permanent-magnet synchronous motor benchmark study," IEEE Transactions on Industry Applications, vol. 49, no. 3, pp. 1268 1275, May 2013.

[23] D. M. Ionel and M. Popescu, "Ultrafast finite-element analysis of brushless pm machines based on space-time transformations," IEEE Transactions on Industry Applications, vol. 47, no. 2, pp. 744-753, Mar. 2011.

[24] G. Sizov, D. M. Ionel, and N. A. O. Demerdash, "Modeling and parametric design of permanent-magnet ac machines using computationally efficient finite-element analysis," IEEE Transactions on Industrial Electronics, vol. 59, no. 6, pp. 2403-2413, June 2012.

[25] T. J. E. Miller, M. Popescu, C. Cossar, M. McGilp, and J. A. Walker, "Calculating the interior permanent-magnet motor," in IEEE International Conference on Electric Machines and Drives, vol. 2, June 2003, pp. 1181-1187 vol.2. on Optimization of Electrical and Electronic Equipment (OPTIM), May 2014, pp. 260-267.

[27] J. F. Eastham, D. M. Ionel, M. J. Balchin, T. Betzer, and E. Demeter, "Finite element analysis of an interior-magnet brushless dc machine, with a step-skewed rotor," IEEE Transactions on Magnetics, vol. 33, no. 2, pp. 2117-2119, Mar 1997. 